\title{
Peran Kepuasan Pelanggan dalam Memediasi Pengaruh Servicescape terhadap Revisit Intention
}

Submitted Date:

26 Maret 2021

Accepted Date:

24 Mei 2021

\section{Suggested Citation}

Biondo, A.E., Bonaventura, L. 2017. Agricultural resources allocation and environmental sustainability. Journal of Applied Economic Sciences, Volume XII, Spring, 1(23): 105 - 113.

Abstract:

In the current millennial era, guiding business people, especially in the service sector, to provide the best service. This study aims to analyze the effect of servicescape on revisit intention with customer satisfaction as a mediating variabel. Data collection was obtained by distributing questionnaires online. The population in this study were visitors to Roketto cafe Malang with purposive sampling as a sample determination with the criteria of having visited at least once. The sample used in this study were 186 respondents. The research data were analyzed using path analysis techniques with analysis tools using Partial Least Square (PLS). The facts found in this study are servicescape has a positive and significant effect on customer satisfaction, customer satisfaction has a positive and significant effect on revisit intention, servicescape has a positive and significant effect on revisit intention, and servicescape has a positive and significant effect on revisit intention through customer satisfaction.

Keywords: revisit intention, satisfaction customer, servicescape

\section{Abstrak:}

Di Era milenial saat ini menuntun pelaku bisnis khususnya dibidang jasa untuk memberikan pelayanan yang terbaik. Penelitian ini bertujuan untuk menganalisis pengaruh servicescape terhadap revisit intention dengan kepuasan pelanggan sebagai variabel mediasi. Pengumpulan data diperoleh dengan menyebarkan kuesioner secara online. Populasi dalam peneltian ini adalah pengunjung pada Roketto cafe Malang dengan purposive sampling sebagai penetuan sampel dengan kriteria perah berkunjung minimal 1 kali. Adapun sampel yang digunakan dalam apenelitian ini sebanyak 186 responden. Data penelitian ini dianalisis menggunakan teknik analisis jalur dengan alat analisis menggunakan Partial Least Square (PLS). Fakta yang ditemukan dalam penelitian ini adalah servicescape berpengaruh positif dan signifikan terhadap kepuasaan pelanggan, kepuasan pelanggan berpengaruh positif dan signifikan terhadap revisit intention, servicescape berpengaruh positif dan signifikan terhadap revisit intention, dan servicescape berpengaruh positif dan signifikan terhadap revisit intention melalui kepuasa pelanggan.

Kata Kunci: kepuasan pelanggan, revisit intention, servicescape, 


\section{Latar Belakang}

Life style atau gaya hidup masyarakat di era milenial saat ini mengakibatkan kebutuhan masyarakat menjadi lebih dinamis. Berbagai jenis kebutuhan masyrakat beraneka ragam, mulai dari kebutuhan primer, sekunder dan pelengkap. Salah satu dari kebutuhan primer tersebut adalah makanan dan minuman. Restoran atau café menjadi pilihan yang tepat untuk memenuhi kebutuhan makanan dan minuman masyarakat saat ini. Belakangan ini bisnis dibidang kuliner sangat digemari para pelaku bisnis. Tingginya animo masyarakat membuat pelaku bisnis dibidang kuliner belomba-lomba untuk mendapatkan pangsa pasar.

Keunggulan kompetitif sangat diperlukan agar mensukseskan usahanya, biasanya para pelaku bisnis memiliki strategi sedemikian rupa agar mampu menjadi pembeda dan bertahan untuk melawan kompetitor sejenis (Heizer \& Render, 2014). Hadirnya restoran atau cafe saat ini dinilai adanya peran teknologi saat ini memudahkan para pelaku bisnis untuk mewujudkan strategi yang akan diterapkan, salah satunya adalah servicescape. Servicescape merupakan kondisi lingkungan layanan yang dapat memepengaruhi perilaku pelanggan terhadap lingkungan layanan seperti kualitas yang dirasakan seperti rasa puas, senang, dan nyaman (Fitzsimmons et al., 2014). Penerapan servicescape dinilai pilihan yang tepat digunakan untuk mendapatkan perhatian calon pelanggan. Servicescape juga dipandang sebagai lingkungan layanan yang diciptakan untuk pelanggan dan pelanggan dan penyedia layanan dapat berinteraksi (Situmorang, 2018). Tujuan dari penerapan servicescape adalah untuk memuaskan pelanggan (Ariani, 2009).

Telah banyak penelitian yang dilakukan untuk mengukur tingkat kepuasan pelanggan yang dipengaruhi servicesacpe. Kepuasan pelanggan merupakan Suatu perasaan yang muncul ketika seseorang telah mendapatkan apa yang diinginkan (Roz, 2019). Hasil temuan Shen \& Bae, (2018) mengungkapkan bahwa komposisi servicescape yang baik berkontribusi pada pembentukan kepuasan pelanggan. Hal ini diperkuat dengan temuan (Rijae, Zaki Muafa, 2018) bahwa kondisi disekitar, tata ruang, fungsi serta symbol, dan artefak berpengaruh positif signifikan terhadap kepuasan pelanggan.

Selain untuk memuaskan pelanggan, servicescape bertujuan untuk mempengaruhi niat seseorang untuk berkunjung kembali (revisit intention). Niat untuk mengunjungi terjadi ketika seseorang tersebut menilai bahwa apa yang merasa rasakan sesuai dengan apa yang diharapkan. Menurut (Banerjee \& Singhania, 2018) revisit intention diartikan sebagai bentuk evaluasi yang dilakukan seseorang atas pengalaman atas kepuasan yang didapatkan secara keseluruhan dan mempengaruhi perilaku dimasa depan dan keinginan untuk kembali ke tempat tujuan yang sama dan merekomendasikan kepada orng lain.

Hasil temuan lain mengungkapkan hal yang berbeda (Situmorang, 2018) mengungkapkan bahawa implementasi serviscape memberikan pengaruh positif tetapi tidak signifikan terhadap revisit intention. Abuthahir \& Krishnapillai, (2018) mengungkapkan hal yang sama bahwa Ambient Conditions tidak berpengaruh terhadap revisit intention sedangkan 2 dimensi lain yang membentuk servicescape yaitu Spatial and Functionality dan Signs, Symbols, and Artifacts berpengaruh positif tetapi tidak signifikan. Dengan adanya perbedaan hasil temuan pada penelitian sebelumnya, maka perlunya penelitian ini untuk dilakukan.

Di Kota Malang bisnis kuliner dan café masih menjadi pilihan pelaku bisnis untuk mengembangkan usahanya. Kota Malang menjadi salah satu destinasi wisatawan baik dalam maupun luar negeri menjadikan alasan yang paling tepat untuk pelaku bisnis membangun usahanya. Berdasarkan Badan Pusat Statistik (BPS) Kota Malang yang baru diperbaharui pada tanggal 10 Januari 2020 terjadi peningkatan cukup signifikan ditahun belakangan ini.

Tabel 1. Jumlah Restoran di Kota Malang (2016-2019)

\begin{tabular}{cc}
\hline Tahun & Jumlah Restoran \\
\hline 2016 & 723 \\
2017 & 706 \\
2018 & 1444 \\
2019 & 1576 \\
\hline
\end{tabular}

Sumber: Dinas Kebudayaan dan Pariwisata Kota Malang (2020)

Dari tabel 1 dapat dilihat bahwa terjadi peningkatan jumlah restoran dan cafee di kota Malang pada 2018. Peningkatan jumlah restoran dan café di kota Malang menunjukkan bahwa kebutuhan makanan dan minuman dikalangan masyarakat bergeser cenderung memilih restoran dan café sebagai solusi permasalahan yang dihadapi. Rokketo Café merupakan salah satu café yang menerapkan servicescape untuk menciptakan kepuasan pengunjungnya di kota Malang. Roketto café berdiri mulai tahun 2018. Mengusung konsep café bernuasa unik dan bergaya ala Jepang serta kekinian menjadikan rokketo café menjadi salah satu pilihan tempat 
berkumpul para kaum milenial di Kota Malang. Dikutip dari Google review terdapat 1.880 ulasan positif, 4,5 dari 5 rating penilaian serta durasi waktu (1-3 jam) pelanggan menghabiskan waktunya untuk mengunjungi roketto café.

Berdasarkan penjelasan fenomena yang telah diungkapkan diatas, maka peneliti tertarik untuk melakukan penelitian mengenai servicescape, kepuasan pelanggan, dan pengaruhnya terhadap revisit intention. Adapun tujuan penelitian ini dilakukan adalah untuk mengetahui pengaruh servicescape, kepuasan pelanggan, dan pengaruhnya terhadap revisit intention pada rokketo café di Kota Malang.

\section{Kajian Literatur}

\section{Servicescape (Lingkungan Layanan)}

Perkembangan servicesacpe didunia kuliner saat ini berkembang dengan pesat khususnya pada perusahaan jasa. Untuk menciptakan pengalaman yang berkesan bagi pelanggan merupakan tantangan yang harus dihadapi oleh perusahaan. Layanan jasa bersifat abstrak dan tidak berwujud (itangible) sehingga pelanggan sangat jeli menilia setiap aspek yang ada dalam perusahaan jasa. Salah satu aspek tersebut adalah servicescape (Lam et al., 2011). Fitzsimmons et al., ( 2014) mendefinisikan servicescape sebagai lingkungan layanan yang dapat memepengaruhi perilaku pelanggan terhadap lingkungan layanan seperti kualitas yang dirasakan seperti rasa puas, senang, dan nyaman. Servicescape juga dapat diartikan sebagai penyamapaian bentuk jasa yang divisualisasikan kedalam bentuk lingkungan layanan dan dapat berinteraksi dengan pelanggan (Rashid et al., 2015)

\section{Kepuasan Pelanggan}

Kepuasan Pelanggan dapat diartikan sebagai perasaan yang muncul yang dirasakan pihak yang akan membeli atau menikmati layanan yang akan diberikan oleh pemasok atau penyedia (Roz, 2019). Seseorang yang akan menjadi pelanggan tentulah akan melakukan interaksi dengan dengan penyedia layanan. Tjiptono, (2017) kepuasan pelanggan merupakan bentuk evaluasi purnabeli antara persepsi terhadap kinerja alternative baik produk ataupun jasa yang telah dipilih untuk melebihi harapan. Kepuasan pelanggan dapat menjadikan keadaan emosional seseorang dapat berupa kemarahan, kekecewaan, kejengkelan, dan kesenangan. Penelitian Rijae, Zaki Muafa, (2018) mengungkapkan bahwa kepuasan pelanggan merupakan hal terpenting yang harus dirasakan seseorang ketika melakukan interaksi dengan penyedia layanan. Sejalan dengan penelitian sebelumnya Pidada \& Wandebori, (2016) mendefinisikan bahwa kepuasan pelanggan sebagai ringkasan keadaan psikologis yang dicapai ketika harapan sesuai dengan apa yang dinginkan. Kepuasan yang dirasakan pelanggan dipengaruhi perbandingan layanan yang dipahami dengan pelayanan yang diharapkan, dan sebagai reaksi emosional jangka pendek pelanggan terhadap kinerja dari sebuah bentuk layanan yang didapatkan.

\section{Revisit Intention}

Sebuah perusahaan khususnya dibidang jasa menawarkan produk berupa layanan yang tujuanya adalah untuk meningkatkan nilai konsumen yang ada, dan menerapkan strategi yang tepat untuk menarik seorang pelnggan untuk datang kembali. Niat berkunjung kembali atau yang lebih dikenal dengan revisit intention merupakan bentuk loyalitas pelanggan terhadap produk atau jasa yang telah melayaninya (Oh \& Oh, 2018). Menurut Banerjee \& Singhania, (2018) revisit intention diartikan sebagai bentuk evaluasi yang dialukan seseorang atas pengalaman atas kepuasan yang didapatkan secara keseluruhan dan mempengaruhi perilaku dimasa depan dan keinginan untuk kembali ke tempat tujuan yang sama dan merekomendasikan kepada orng lain (Zhang et al., 2018). Penelitian yang dilakukan Kwon \& Woo, (2015)juga mengungkapkan hal yang sama bahwa revisit intention merupakan perilaku seseorang yang telah merasakan kepuasan untuk datang kembali dan merasakan hal yang sama dimasa lalu.

\section{Keterkaitan Servicesacpe dan Kepuasan Pelanggan}

Fitzsimmons et al., ( 2014) menjelaskan bahwa servicescape dibentuk oleh Ambient Conditions, Spatial and Functionality, dan Signs, Symbols, and Artifacts. Sejalan dengan penjelasan tersebut, Kwon \& Woo, (2015) uga menjelaskan bahwa kondisi lingkungan di perusahaan dipengaruhi oleh suasana, atmosfir, suhu, cahaya, aroma, music dan pencahayaan. Kondisi lingkungan layanan yang baik dan sesuai dengan persepsi pelanggan 
menimbulkan kepuasan dari sisi pelanggan. Penelitian Rashid et al., (2015) mejelaskan pengaruh servicescape terhadap kepuasan pelanggan, hasilnya kondisi sekitar, tata ruang / fungsi, dan tanda, simbol, artefak mempengaruhi kepuasan pelanggan. Rijae, Zaki Muafa, (2018) menemukan hal yang serupa bahwa kondisi sekitar, tata ruang dan fungsi serta tanda, simbol, dan artefak berpengaruh positif signifikan terhadap kepuasan pelanggan. Berdasarkan uraian yang telah dijelaskan sebelumnya, maka dapat ditarik hipotesis pertama $(\mathrm{H} 1) \mathrm{di}$ dalam penelitian ini adalah Servicescape berpengaruh positif dan signifikan terhadap kepuasan pelanggan

\section{Keterkaitan Servicescape dan Revisit Intention}

Berbicara bisnis dibidang jasa, salah satu faktor terpenting yang menjadi perhatian khusus adalah kondisi layanan. Servicesscape merupakan perwujudan bentuk layanan yang dapat dirasakan pelanggan dan dapat berinteraksi antara penyedia layanan dan pengguna layanan (konsumen) (Ariani, 2009). Ketika seseorang telah melakukan interaksi sebelumnya dengan kondisi layanan ada 2 hal yang ada dipersepsi pelanggan yaitu ingin mengunjungi kembali atau tidak (Abuthahir \& Krishnapillai, 2018). Sejalan dengan penjelasan tersebut, Penelitian (Oh \& Oh, 2018) mengemukanan bahwa atmosfir, kenyamana peralatan elektonik, mempengauhi pandangan pengunjung mempengaruhi seseorang untuk niat mengunjungi kembali, sehingga perlu memberikan servicescape yang lebih baik kepada para pengunjung. (Ayunisa, 2018) juga memperkuat hasil temuas sebelumnya, bahwa dengan menerapkan strategi servicescape yang baik, dapat meningkatkan niat mengunjungi kembali kepada pelanggan. Berdasarkan penjelasan diatas, maka dapat ditarik hipotesis kedua $(\mathrm{H} 2)$ di dalam penelitian ini adalah servicescape berpengaruh positif dan signifikan terhadap revisit intention.

\section{Keterkaitan Kepuasan Pelanggan dan Revisit Intention}

Kepuasan Pelanggan dapat diartikan sebagai perasaan yang muncul yang dirasakan pihak yang akan membeli atau menikmati layanan yang akan diberikan oleh pemasok atau penyedia produk/ jasa. Menurut Tjiptono, (2017) kepuasan pelanggan merupakan bentuk evaluasi purna beli dimana alternatif yang dipilih setidaknya melebihi harapan dari pelanggan tersebut. Rasa puas yang dirasakan pelanggan mengakibatkan seorang untuk melakukan niat berkunjungan kembali. Muslikhah et al., (2016) mengungkapan bahwa niat berkunjung Kembali merupakan hasil kepuasan yang dirasakan seseorang akan produk atau jasa yang telah dirasakan. Lebih lanjut Nguyen Viet et al., (2020) menjelaskan adanya hubungan yang kuat antara kepuasan pelanggan dan niat seseorang untuk mengunjung kembali. Sejalan dengan penelitian sebelumnya, penelitian yang dilakukan $\mathrm{Ha}$ et al., (2010) membuktikan salah satu yang menyebabkan seseorang untuk berkijung kembali karena merasakan kepuasan. Berdasarkan penjelasan yang telah diuraikan peneliti, maka dapat ditarik hipotesis ketiga $(\mathrm{H} 3)$ yakni kepuasan pelanggan berpengaruh positif dan signifikan terhadap revisit intention.

\section{Keterkaitan Servicescape, Kepuasan Pelanggan, dan Revisit Intention}

Penerapan strategi kondisi fisik yang selama ini diterapkan penyedia saja merupakan cara untuk mendapatkan kepuasan pelanggan (Fitzsimmons et al., 2014). Penelitian yang dilakukan Shen \& Bae, (2018) mengemukanan hasil bahwa servicescape memberikan pengaruh yang baik terhadap kepuasan pelanggan. Kondisi layanan yang sesuai dengan persepsi pelanggan menimbulkan pengalaman yang sulit untuk dilupakan dan rasa puas yang dirasakan. Kepuasan yang muncul dibeberapa pelanggan dapat memunculkan niat untuk mengunjungi kembali. Sesuai dengan penelitian Pidada \& Wandebori, (2016) menjelaskan bahwa kepuasan yang dirasakan konsumen berpengaruh positif dan signifikan untuk meningkatakn tingkat niat berkunjung kembali. Temuan Suhud \& Wibowo, (2016) memperkuat hasil penelitian sebelumnya bahwa kepuasan konsumen secara signifikan dipengaruhi oleh persepsi nilai dan atmosfer restoran, dan kepuasan konsumen secara signifikan mempengaruhi intensi berkunjung kembali. Penelitian lain juga menjelaskan bahwa kepuasan yang dirasakan pelanggan ketika beinterkasi langsung dengan kondisi layanan akan menimbulkan niat untuk mengunjungi kembali. Lam et al., (2011) mengungkapkan suasana, navigasi, kenyamanan tempat duduk, dekorasi interior, dan kebersihan memengaruhi kepuasan kognitif dan afektif dari pelanggan dan mempengaruhi niat seseorang untuk mengunjungi kembali. Berdasarkan penjelasan yang telah diuraikan peneliti, maka dapat ditarik hipotesis keempat $(\mathrm{H} 4)$ yakni servicescape berpengaruh terhadap revisit intention melalui kepuasan pelanggan.

\section{Metode Penelitian}

Penelitian ini menggunkan pendekatan kuantitatif. Populasi dalam penelitian ini adalah pengunjung Café Roketo di kota Malang. Tahapan selanjutnya adalah pengambilan sampel. Pengambil sampel dengan Purposive Sampling dengan kriteria pengunjung yang pernah mengunjungi Roketo café lebih dari 1 kali. Menurut Hair et al., (2014) enjelaskan bahwa penetapan jumlah sampel minimal dengan variabel $\leq 5$ maka jumlah sampel yang 
harus dipenuhi sebesar 100, sedangkan untuk variabel $\leq 7$ minimal sebesar 150 , variabel $\geq 7$ minimal sebesar 300 , dan model dengan variabel yang sangat banyak minimal sebesar 500 . Adapun definisi operasional yang digunakan dalam penelitian ini sebagai berikut : Sevicescape terdiri dari 3 dimensi (Fitzsimmons et al., 2014) : (1) ambient conditions, (2) spatial and functionality, dan (3) signs, symbols, and artifacts. Kepuasan pelanggan (Situmorang, 2018) tediri dari 3 dimensi : (1) value, (2) price, (3) quality, dan Variabel Revisit Intention terdiri dari 4 dimensi (Baker \& Crompton, 2000) terdiri dari 4 dimensi : (1) intent to recommend, (2) intent to revisit, (3) intent to purchase, dan (4) intent to positive tale. Penelitian ini menggunakan perangkat lunak Partial Least Square (PLS) untuk menganalisis data. Tiga langkah yang dilakukan yaitu mengevaluasi inner model, outer model dan uji hipotesis.

\section{Hasil}

Berdasarkan hasil pengumpulkan data primer dengan menggunakan kuesioner, terdapat 186 jumlah responden yang sesuai dengan kriteria yang sebelumnya sudah dijelaskan oleh peneliti. Adapun penjelasanya dapat dilihat pada tabel 2 meliputi deografi responden. Berdasarkan tabel 2 tersaji data responden dengan kriteria meliputi jenis kelamin, usia, durasi perkunjung, dan intensitas berkunjung. Dari tabel diatas menujukkan pengunjung berjenis kelamin perempuan sebesasar $55.91 \%$ mendominasi dibandingkan dengan responden laki-laki. Berdasarkan usia, pengunjung dengan rentang usia 22 - 25 tahun mendominasi sebesar $50.54 \%$. Hal ini dapat dimaknai bahwa orang dengan rentang usai tersebut masuk dalam usia produktif dan lebih suka berinteraksi dengan orang lain dalam menjalni aktivitas diluar rumah. Berdasarkan durasi berkuunjung waktu antara $2-3$ mendominasi sebesar $47.32 \%$. Fakta ini menunjukkan rentang durasi tersebut dinilai cukup untuk melakukan aktivitas dan berinteraksi dengan orang lain dalam menjalanai hubungan social, sedangkan berdasarkan intenstitas berkunjunga dalam sebulan didominasi sebanyak 3 kali dalam sebulan atau sebesar $60,22 \%$. Hal ini dimaknai sebagai intensitas yang cukup untuk mengunjungi dan melakukan aktivitas social yang dirasa aman dan nyaman untuk melalukan sesuatu yang dianggap penting.

Tabel 2. Demografi Responden

\begin{tabular}{lcc}
\multicolumn{1}{c}{ Demografi Responden } & Frekuensi & Persentase (\%) \\
Jenis Kelamin & & \\
Laki-laki & 82 & 44.09 \\
Perempuan & 104 & 55.91 \\
Usia & 0 & \\
$<17$ tahun & 68 & 0 \\
$18-21$ tahun & 94 & 36.56 \\
$22-25$ tahun & 24 & 50.54 \\
$>25$ tahun & & 12.90 \\
Durasi Berkunjung & 6 & \\
$<1$ jam & 12 & 3.22 \\
$1-2$ jam & 88 & 6.45 \\
$2-3$ jam & 80 & 47.32 \\
$>3$ jam & & 43.01 \\
Intensitas Berkunjung (dalam sebulan) & 0 & \\
1 & 34 & 0 \\
2 & 112 & 18.27 \\
3 & 40 & 60.22 \\
4 & & 21.51 \\
\hline
\end{tabular}

Sumber: Data primer diolah, 2020

Setelah mendapatkan data yang diperoleh dari kuesioner, selanjutnya dilakukan uji validitas dan reliabilitas untuk menilai keandalan item-item maupun indikator didalam penelitian ini. Uji validitas dan reliabilitas pada partial least square tersaji dalam output outer loading, AVE, dan composite reliability. Berikut adalah hasil dari uji validitas dan reliabilitas di dalam penelitian ini: 
Tabel 3. Outer Loading dan Composite Reliability

\begin{tabular}{lcccc}
\hline Variabel & Dimensi & Outer Loading & AVE & Composite Reliability \\
\hline Servicescape & S1 & 0,915 & 0.818 & 0,931 \\
& S2 & 0.900 & & \\
\hline S3 & 0.897 & & 0,865 \\
& KP1 & 0.804 & 0.681 & \\
\hline KP2 & 0.812 & & 0,876 \\
KP3 & RI1 & 0.858 & 0.640 & \\
& RI2 & 0.792 & & \\
& RI3 & 0.771 & & \\
& RI4 & 0.828 & & \\
\hline
\end{tabular}

Sumber: Data primer diolah, 2020

Berdasarkan tabel 3 menyajikan hasil evaluasi outer model seluruh indikator dalam penelitian ini memiliki nilai outer loading dan nilai average variance extracted (AVE) > 0.5. Menurut (Ghozali, 2013) nilai AVE diharapakan lebih besar dari 0.5 jika ingin model penelitian dikatakan baik. Hal ini dapat disimpulkan bahwa seluruh dimensi pengukuran konstruk dinyatakan valid. Sedangkan menurut (Chin, 2010) diharapkan nilai composite reability diatas 0.7 . Terlihat dari ke 3 variabel yang digunakan dalam penelitian ini memiliki nilai composite reliability $>0.7$

Tabel 4. Hasil Pengujian Hipotesis

\begin{tabular}{|c|c|c|c|c|c|}
\hline Hipotesis & Path Analysis & Coefficient & T-statistic & P-Value & Keterangan \\
\hline \multicolumn{6}{|c|}{ Pengaruh Langsung } \\
\hline $\mathrm{H} 1$ & $\mathrm{~S} \rightarrow \mathrm{KP}$ & 0.696 & 12.070 & 0.000 & Sig. \\
\hline $\mathrm{H} 2$ & $\mathrm{KP} \rightarrow \mathrm{RI}$ & 0.458 & 8.070 & 0.000 & Sig. \\
\hline H3 & $\mathrm{S} \rightarrow \mathrm{RI}$ & 0.541 & 10.012 & 0.000 & Sig. \\
\hline \multicolumn{6}{|c|}{ Pengaruh Tidak Langsung } \\
\hline $\mathrm{H} 4$ & $\mathrm{~S} \rightarrow \mathrm{KP} \rightarrow \mathrm{RI}$ & 0.432 & 6.795 & 0.000 & Sig. \\
\hline
\end{tabular}

Sumber: Data primer diolah (2020)

Berdasarkan hasil pengujian antar variabel, hipotesis dapat diterima jika thitung lebih besar dari t tabel $(1,96)$ atau $p$ values lebih kecil dari 0,05 (Ghozali, 2013). Berdasarkan hasil pengujian pada tabel 4 , dapat dilihat bahawa semua hubungan antara variabel yaitu : servicescape terhadap kepuasan pelanggan, kepuasan pelanggan terhadap revisit intention, servicescape terhadap revisit intention memiliki nilai thitung lebih besar dari t tabel $(1,96)$. Hal ini dapat disimpulkan bahwa ke 3 hipotesis diajukan diterima yang berarti servicescape berpengaruh positif dan signifikan terhadap kepuasan pelanggan, kepuasan pelanggan berpengaruh positif terhadap revisit intention, dan servicescape berpengaruh positif dan signifikan terhadap revisit intention. Hipotesis ke 4 dalam penelitian ini juga memiliki thitung $>t$ tabel artinya variabel kepuasan pelanggan mampu memediasi pengaruh servicescape terhadap revisit intention. Secara keseluruhan ke 4 hipotesis yang diajukan peneliti dapat diterima.

\section{Goodness of Fit Model}

Pengukuran ini digunakan untuk mengerahui sejauh mana inner model yang terdapat dalam penelitian ini. Masing-masing variabel endogen yang dinyatakan dengan Nilai $R^{2}$ antara lain : (1) Variabel endogen kepuasan pengunjung bernilai 0.485 atau sebesar $48.5 \%$ kepuasan pengunjung dipengaruhi oleh servicesacpe. (2) Variabel endogen revisit intention bernilai 0.850 atau sebesar $85 \%$ revisit intention dipengaruhi oleh servicescape dan kepuasan pengunjung. Dan nilai predictive relevance $\left(Q^{2}\right)$ dapat dihitung sebagai berikut :

$$
\begin{aligned}
& Q^{2}=1-\left(1-R_{1}{ }^{2}\right)\left(1-R_{2}{ }^{2}\right) \\
& Q^{2}=1-\left(1-0.485^{2}\right)\left(1-0.850^{2}\right) \\
& Q^{2}=1-(1-0.231)(1-0.720) \\
& Q^{2}=1-0.215 \\
& Q^{2}=0.785
\end{aligned}
$$

Perhitungan diatas menunjukkan nilai yang tinggi sebesar 0.785 sehingga model model layak dinyatakan memiliki nilai predictive-relevance. Hasilnya sebesar $78.5 \%$ menggambarkan keragaman data yang dapat 
dijelaskan oleh model PLS atau informasi yang terkandung dalam data dapat dijelaskan oleh model tersebut. Sedangkan sebesar $21.5 \%$ dijelaskan oleh variabel lain diluar variabel yang diteliti.

\section{Pembahasan}

\section{Pengaruh Servicescape terhadap Kepuasan Pelanggan}

Hasil penelitian ini membuktikan bahwa servicescape berpengaruh positif dan signifikan terhadap kepuasan pelanggan pada Roketto café di Kota Malang. Servicescape merupakan salah satu bentuk kenggulan kompetitif yang dimiliki sebuah layanan dalam menarik calon pelanggan (Fitzsimmons et al., 2014). Dengan menerapkan servicescape memberikan sisi positif terhadap citra perusahaan. Servicescape dinilai penting untuk menarik perhatian konsumen dan dapat memberikan sensasi hedon (Dedeoglu et al., 2018). Hasil penelitian ini mendukung penelitian sebelumnya dilakukan Shen \& Bae, (2018) mengungkapkan bahwa adanya servicescape memberikan efek yang signifikan terhadap kepuasan pelanggan. Pelanggan merasa puas dengan kondisi fisik seperti penataan layout, pencahayaan, serta memberikan music sebagai bentuk relaksasi ketika datang dan menikmati layanan yang diberikan (Demoulin \& Willems, 2019).

Temuan penelitian ini juga memperkuat penelitian yang dilakukan Oviedo et al., (2019) mengungkapkan dengan memberikan symbol, petunjuk serta penataan layout yang tepat akan meningkatkan kepuasan seseorang. Hasil temuan penelitian ini memberikan gambaran yang jelas bahwa perusahaan atau usaha bisnis harus memiliki kondisi lingkungan fisik yang baik guna menarik calon pelanggan untuk menikmati/ menggunakan produk yang dijual. Hal ini dimaknai semakin baik kondisi fisik yang diciptakan oleh pemiliki café maka semakin tinggi tingkat kepuasan yang dirasakan pelanggan. Dari hasil pengamatan Roketto café telah berhasil menerapkan servicescape dengan baik, hal ini terlihat dengan tingkat kepuasan yang dirasakan pelanggan selama berinteraksi dengan servis yang diberikan.

\section{Pengaruh Kepuasan Pelanggan terhadap Revisit Intention}

Berdasarkan hasil penelitian yang telah dilakukan peneliti, membuktikan bahwa kepuasan pelanggan berpengaruh positif dan signifkan terhadap revisit intention pada Roketto café di Kota Malang. Kepuasan Pelanggan dapat diartikan sebagai perasaan yang muncul yang dirasakan pihak yang akan membeli atau menikmati layanan yang akan diberikan oleh pemasok atau penyedia (Roz, 2019). Kepuasan juga dinilai sebagai perbandingan antara persepsi dan harapan sesorang ketika melakukan interaksi (Jufrizen et al., 2020). Tjiptono, (2017) kepuasan pelanggan merupakan bentuk evaluasi purnabeli antara persepsi terhadap kinerja alternative baik produk ataupun jasa yang telah dipilih untuk melebihi harapan. Hasil temuan penelitian ini mendukung temuan penelitian sebelumnya, Pidada \& Wandebori, (2016) membuktikan bahwa kepuasan pelanggan memberikan dapat yang signifikan terhadap seseorang untuk datang kembali.

Ketika seseorang puas dengan yang dirasakan kemungkinan besar akan memunculkan niat untuk mengunjungi kembali. Hal ini diperkuat dengan temuan $\mathrm{Wu},(2018)$ mengemukanan rasa puas yang dirasakan seseorang akan memberikan keinginan untuk datang kembali dan merekomendasikan ke orang lain untuk datang. Sejalan dengan temuan lain diungkapakan Lee \& Kim, (2017) niat berkunjung kembali muncul ketika seseorang telah merasakan apa yang diharapkan dan memberikan dampak positif untuk merekomendasikan kepada orang lain. Dari hasil penelitian yang telah dilakukan terbukti tingkat kepuasan pelanggan pada Roketto café tinggi dan memberikan dampak terhadap niat pelanggan untuk datang kembali. Hal ini dibuktikan dengan intestitas pelanggan dalam sebulan mengunjungi 3 kali dalam sebulan. Semakin tinggi tingkat kepuasan pelanggan pada Roketto café dikota Malang berbanding lurus dengan niat pelanggan untuk melakukan revisit intention.

\section{Pengaruh Servicescape terhadap Revisit Intention}

Hasil penelitian ini membuktikan bahwa servicescape berpengaruh positif dan signifikan terhadapa revisit intention pada Roketto café di Kota Malang. Revisit intention merupakan bentuk evaluasi yang dilakukan seseorang atas pengalaman atas kepuasan yang didapatkan secara keseluruhan dan mempengaruhi perilaku dimasa depan dan keinginan untuk kembali ke tempat tujuan yang sama dan merekomendasikan kepada orng lain (Zhang et al., 2018). Lebih lanjut revisit intention dinilai sebagai tindakan yang dilakukan secara berulang untuk mengunjungi tempat atau layanan yang diberikan karena adanya rasa puas (Meng \& Choi, 2018). Penelitian ini didukung oleh hasil temuan Ayunisa, (2018) membuktikan bahwa servicescape memberikan 
dampak yang signifikan terhadap revisit intention dengan menerapkan ambient condition, spatial layout, facility aesthetics dan signs.

Lebih lanjut penelitian Oh \& Oh, (2018) menjelaskan dengan menerapkan servicescape seperti penempatan peralatan elektornik yang pas dan sesuai memiliki efek positif pada niat orang untuk melakukan kunjungan kembali. Abuthahir \& Krishnapillai, (2018) memperkuat hasil temua lainya yaitu dengan pencahayaan, musik, dekorasi, kebersihan, dan tata ruang secara signifikan memengaruhi niat kunjungan kembali pelanggan. Berdasarkan hasil penelitian ini membuktikan bahwa servicescape yang telah diterapkan Roketto café memberikan efek kepada pelanggan untuk melakukan revisit intention. Hal ini dapat disimpulkan semakin baik servicescape yang diberikan kepada pelanggan maka semakin tinggi juga niat untuk melakukan kunjungan kembali.

\section{Pengaruh Servicescape terhadap Revisit Intention melalui Kepuasan Pelanggan}

Hasil penelitian ini membuktikan bahwa kepuasan pelanggan mampu mediasi pengaruh servicescape terhadap revisit intention pada Roketto café di kota Malang. Kepuasan yang dirasakan pengunjung dipengaruhi adanya kondisi fisik yang mendukung yang mengakibatkan munculnya niat untuk berkunjung kembali. Lingkungan fisik, navigasi, kenyamanan tempat duduk, dekorasi interior, dan kebersihan memengaruhi kepuasan kognitif dan afektif seorang pengunjung untuk memberikan kesan yang tidak tidak terlupakan. Hasil penelitian ini sejalan dengan penelitian terdahulu yang dilakukan Suhud \& Wibowo, (2016) memperkuat hasil penelitian sebelumnya bahwa kepuasan konsumen secara signifikan dipengaruhi oleh persepsi nilai dan atmosfer restoran, dan kepuasan konsumen secara signifikan mempengaruhi intensi berkunjung kembali. Hal serupa juga dikemukakan Kwon \& Woo, (2015) menunjukkan bahwa servicescape mempengaruhi kepuasan pelanggan dan niat mengunjungi kembali, dan bahwa kepuasan pelanggan memiliki efek mediasi. Hal serupa juga dikemukakan Banerjee \& Singhania, (2018) tingkat kepuasan seseorang dipengaruhi kondisi fisik yang berdampak niat orang untuk mengunjungi kembali.

\section{Kesimpulan dan Saran}

Berdasarkan kajian yang telah dilakukan, temuan penelitian ini antara lain menyatakan bahwa servicescape berpengaruh positif dan signifikan terhadap kepuasan pelanggan pada Roketto café di kota Malang. Servicescape merupakan suatu kondisi lingkungan fisik yang berujuan untuk memberikan sensasi yang berbeda dan berkesan kepada seseorang yang telah berkunjung untuk memuaskan orang yang telah melakukan interaksi. Kepuasan pelanggan memberikan pengaruh positif dan signifikan terhadap revisit intention pada Roketto café di kota Malang. Kepuasan pelanggan merupakan perasaan yang muncul yang dirasakan pihak yang akan membeli atau menikmati layanan yang akan diberikan oleh pemasok atau penyedia. Rasa puas akan muncul ketika melebih apa yang diharapakan. Dengan munculnya rasa puas yang dirasakan pelanggan akan memunculkan niat untuk datang atau berkunjung kembali. Servicescape berpengaruh positif dan signifikan terhadap revisit intention pada Roktetto café di kota Malang. Servicescape merupakan salah satu bentuk kenuggulan kompetitif yang dimiliki sebuah layanan dalam menarik calon pelanggan. Dengan menerapkan servicescape yang baik akan meningkatkan keunggulan kompetitif khususnya pada penyedia jasa/ layanan dan berdampak munculnya niat untuk mengunjungi kembali. Servicescape berpengaruh positif dan signifikan terhadap Roketto café melalui kepuasan pelanggan pada Roketto café di kota.

Kepuasan yang dirasakan pelanggan mampu memediasi servicescape yang terapkan Roketto café untuk memunculkan niat untuk berkunjung kembali. Semakin baik penerapkan servicescape maka akan berdampak rasa puas yang dirasakan pelanggan dan mengakibatkan pelanggan ingin datang dan berkunjung kembali untuk menikmati lingkungan fisik pada Roketto café di koata Malang. Berdasarkan hasil penelitian ini peneliti memberikan saran kepada Roketto café di kota Malang untuk tetap mempertahankan kondisi lingkungan fisik yang sudah ada, hanya saja tetap perlu mempertimbangkan berkaitan dengan konsep yang telah diusung sehingga tidak memberikan kesan yang monoton. Penelitian selanjutnya hendaknya dapat menambahakn variabel-variabel diluar penelitian yang memiliki hubungan keterkaitan dengan servicescape, kepuasan pelanggan, dan revisit intention sehingga dapat menambah khasanah ilmu di bidang manajemen.

\section{Daftar Pustaka}

Abuthahir, S. B. S., \& Krishnapillai, G. (2018). How does the Ambience of Cafe Affect the Revisit Intention among its Patrons? A $S$ on the Cafes in Ipoh, Perak. MATEC Web of Conferences, 150. https://doi.org/10.1051/matecconf/201815005074 
Ariani, D. orothe. W. (2009). Service Operation Management (1st ed.). Graha IImu.

Ayunisa, F. (2018). Peran Servicescape Dalam Meningkatkan Hotel Image Dan Revisiting Intention Pada Hotel Bintang 5. Jurnal Manajemen Dan Pemasaran Jasa, 9(2), 269. https://doi.org/10.25105/jmpj.v9i2.1676

Baker, D. A., \& Crompton, J. L. (2000). Quality, satisfaction and behavioral intentions. Annals of Tourism Research, 27(3), 785-804. https://doi.org/10.1016/S0160-7383(99)00108-5

Banerjee, S., \& Singhania, S. (2018). Determinants of Customer Satisfaction, Revisit Intentions and Word Of Mouth in the Restaurant Industry-Study Conducted In Selective Outlets of South Kolkata. International Journal of Business and Management Invention (IJBMI) ISSN, 7(6), 63-72. www.ijbmi.org

Chin, W. W. (2010). Handbook of Partial Least Squares. In Handbook of Partial Least Squares.

Dedeoglu, B. B., Bilgihan, A., Ye, B. H., Buonincontri, P., \& Okumus, F. (2018). The impact of servicescape on hedonic value and behavioral intentions: The importance of previous experience. International Journal of Hospitality Management, 72(December 2017), 10-20. https://doi.org/10.1016/j.ijhm.2017.12.007

Demoulin, N., \& Willems, K. (2019). Servicescape irritants and customer satisfaction: The moderating role of shopping motives and involvement. Journal of Business Research, 104(December 2017), 295-306. https://doi.org/10.1016/j.jbusres.2019.07.004

Fitzsimmons, J. A., Fitzsimmons, J. M., \& Bordoloi, S. K. (2014). ervice Management: Operations, Strategy, Information Technology (8th ed.). McGraw-Hill.

Ghozali, I. (2013). Structural Equation Model Amos Concept \& Application 21.0. Badan Penerbit Universitas Diponegoro.

Ha, H. Y., Janda, S., \& Muthaly, S. K. (2010). A new understanding of satisfaction model in e-re-purchase situation. European Journal of Marketing, 44(7), 997-1016. https://doi.org/10.1108/03090561011047490

Hair, J. F., Black, W. C., Babin, B. J., \& E., A. R. (2014). Multivariate Data Analysis (7th Edition). Pearson Education Limited.

Heizer, J., \& Render, B. (2014). Manajemen Operasi (Manajemen Keberlangsungan dan Rantai Pasokan) (11th ed.). Salemba Empat.

Jufrizen, J., Daulay, R., Sari, M., \& Nasution, M. I. (2020). Model Empiris Peningkatan Kepuasan Dan Niat Beli Konsumen Dalam Pemilihan Online Shop Instagram. Mix Jurnal IImiah Manajemen, 10(2), 249. https://doi.org/10.22441/mix.2020.v10i2.008

Kwon, K.-W., \& Woo, S.-K. (2015). The Mediating Effect of Customer Satisfaction in the Relationship between Bakery Cafes Servicescape and Revisit Intention. Journal Economics and Business, 21(6), 14-27.

Lam, L. W., Chan, K. W., Fong, D., \& Lo, F. (2011). Does the look matter? The impact of casino servicescape on gaming customer satisfaction, intention to revisit, and desire to stay. International Journal of Hospitality Management, 30(3), 558-567. https://doi.org/10.1016/j.j.jhm.2010.10.003

Lee, S., \& Kim, E. K. (2017). The Effects of Korean Medical Service Quality and Satisfaction on Revisit Intention of the United Arab Emirates Government Sponsored Patients. Asian Nursing Research, 11(2), 142-149. https://doi.org/10.1016/j.anr.2017.05.008

Meng, B., \& Choi, K. (2018). An investigation on customer revisit intention to theme restaurants: The role of servicescape and authentic perception. International Journal of Contemporary Hospitality Management, 30(3), 1646-1662. https://doi.org/10.1108//JCHM-11-2016-0630

Muslikhah, R. S., Astuti, Y., \& Mahyuddin, M. (2016). Pengaruh Kepuasan Konsumen Dan Kepercayaan Merek Pada Niat Berkunjung Kembali Hotel Di Yogyakarta. Jurnal Manajemen, 5(1). https://doi.org/10.26460/jm.v5i1.185

Nguyen Viet, B., Dang, H. P., \& Nguyen, H. H. (2020). Revisit intention and satisfaction: The role of destination 
image, perceived risk, and cultural contact. Cogent Business and Management, 7(1). https://doi.org/10.1080/23311975.2020.1796249

Oh, S. H., \& Oh, J. W. (2018). The Influence of Servicescape of Exhibition on the Visitors Immersion and Revisit Intention. International Journal of Pure and Applied Mathematics, 118(19), 1703-1715.

Oviedo-García, M. Á., Vega-Vázquez, M., Castellanos-Verdugo, M., \& Orgaz-Agüera, F. (2019). Tourism in protected areas and the impact of servicescape on tourist satisfaction, key in sustainability. Journal of Destination Marketing and Management, 12(February), 74-83. https://doi.org/10.1016/j.jdmm.2019.02.005

Pidada, A. A. P., \& Wandebori, H. (2016). Factors That Influence Revisit Intention To Hospital. Journal of Business and Management, 5(4), 530-539.

Rashid, N. M., Ma'amor, H., Ariffin, N., \& Achim, N. (2015). Servicescape: Understanding how Physical Dimensions Influence Exhibitors Satisfaction in Convention Centre. Procedia - Social and Behavioral Sciences, 211(September), 776-782. https://doi.org/10.1016/j.sbspro.2015.11.167

Rijae, Zaki Muafa, D. (2018). PENGARUH SERVICESCAPE TERHADAP KEPUASAN KONSUMEN ( Studi pada Penumpang Keberangkatan Domestik di Bandara Ahmad Yani Semarang ). Diponegoro Journal Of Management, 7(1), 1-11.

Roz, K. (2019). Analisis Pengaruh Website Quality Terhadap Kepuasan Pelanggan Dengan Menggunakan Metode WebQual 4.0. JURNAL MANAJEMEN DAN KEWIRAUSHAAN, 41-49.

Shen, X., \& Bae, B.-R. (2018). The Effect of Coffee Shop's Servicescape on the Customer Loyalty - Focused on Jeonju Area. Journal of Industrial Distribution \& Business, 9(3), 89-98. https://doi.org/10.13106/ijidb.2018.vol9.no3.89.

Situmorang, S. H. (2018). Influence Of Servicescape, Customer Satisfaction, WOM, and Social Media to Consumer Loyalty (study case bali beach). Advances in Economics, Business and Management Research (AEBMR), 46(February). https://doi.org/10.2991/ebic-17.2018.62

Suhud, U., \& Wibowo, A. (2016). Predicting Customers' Intention to Revisit A Vintage-Concept Restaurant. Journal of Consumer Sciences, 1(2), 56. https://doi.org/10.29244/jcs.1.2.56-69

Tjiptono, A. (2017). Service management (Edisi 3). Andi.

Wu, H. (2018). A Study of Experiential Quality, Experiential Value, Experiential Satisfaction, Theme Park Image , and Revisit Intention (Vol. 42, Issue 1). https://doi.org/10.1177/1096348014563396

Zhang, H., Wu, Y., \& Buhalis, D. (2018). A model of perceived image, memorable tourism experiences and revisit intention. Journal of Destination Marketing and Management, 8(February), 326-336. https://doi.org/10.1016/j.jdmm.2017.06.004 